\title{
Figure Correction: Detecting Screams From Home Audio Recordings to Identify Tantrums: Exploratory Study Using Transfer Machine Learning
}

\author{
Rebecca O'Donovan ${ }^{1}$, BSc; Emre Sezgin ${ }^{1}$, PhD; Sven Bambach ${ }^{1}$, PhD; Eric Butter ${ }^{2}$, PhD; Simon Lin ${ }^{1}$, MD, MBA \\ ${ }^{1}$ The Abigail Wexner Research Institute, Nationwide Children's Hospital, Columbus, OH, United States \\ ${ }^{2}$ Department of Psychology, Nationwide Children's Hospital, Columbus, OH, United States
}

\section{Corresponding Author:}

Emre Sezgin, $\mathrm{PhD}$

The Abigail Wexner Research Institute

Nationwide Children's Hospital

700 Children's Drive

Columbus, OH, 43205

United States

Phone: 16143556814

Email: emre.sezgin@ nationwidechildrens.org

\section{Related Article:}

Correction of: https://formative.jmir.org/2020/6/e18279/

(JMIR Form Res 2020;4(7):e21591) doi: 10.2196/21591

In "Detecting Screams From Home Audio Recordings to Identify Tantrums: Exploratory Study Using Transfer Machine Learning" (JMIR Form Res 2020;4(6):e18279) an error was noticed.
Figure 4 included an incorrect version of the ROC and Precision-Recall curves, which did not reflect the average precision (0.42) and AUC (0.95) reported in the manuscript. Figure 4 has been updated with the correct image and caption.

Figure 4. Results on all Supernanny data. AUC: area under the curve; ROC: receiver operating characteristic.

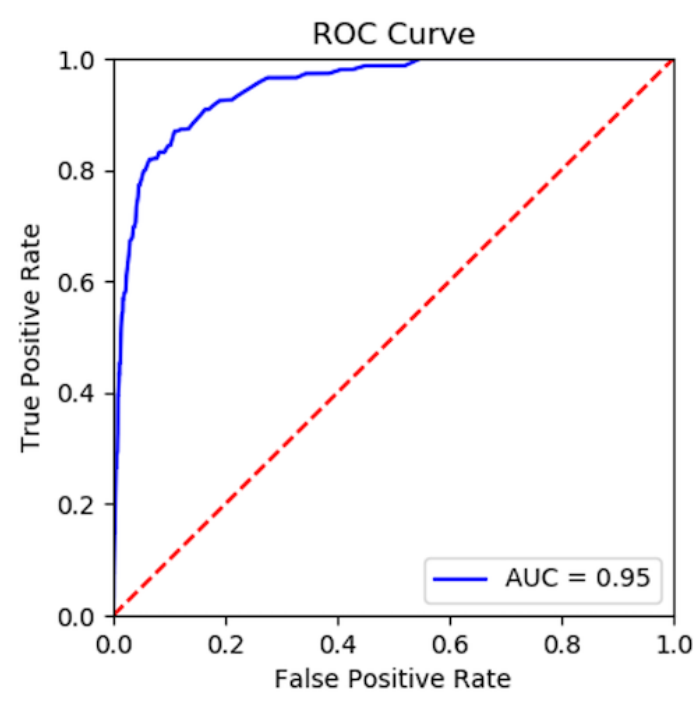

The correction will appear in the online version of the paper on the JMIR website on July 8, 2020, together with the publication of this correction notice. Because this was made after submission

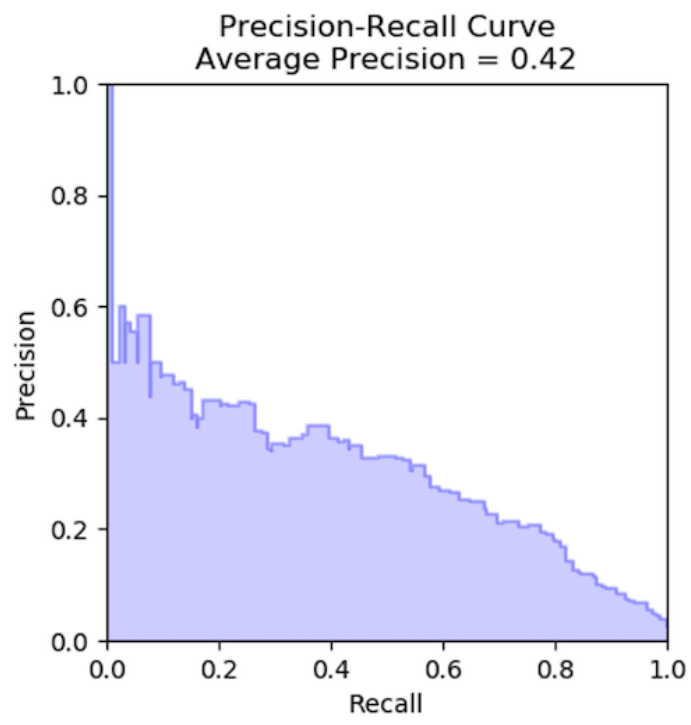

to PubMed, PubMed Central, and other full-text repositories, the corrected article has also been resubmitted to those repositories. 
This is a non-peer-reviewed article. Submitted 18.06.20; accepted 24.06.20; published 08.07.20.

Please cite as:

O'Donovan R, Sezgin E, Bambach S, Butter E, Lin S

Figure Correction: Detecting Screams From Home Audio Recordings to Identify Tantrums: Exploratory Study Using Transfer Machine

Learning

JMIR Form Res 2020;4(7):e21591

URL: https://formative.jmir.org/2020/7/e21591

doi: $10.2196 / 21591$

PMID: $\underline{32673229}$

CRebecca O'Donovan, Emre Sezgin, Sven Bambach, Eric Butter, Simon Lin. Originally published in JMIR Formative Research (http://formative.jmir.org), 08.07.2020. This is an open-access article distributed under the terms of the Creative Commons Attribution License (https://creativecommons.org/licenses/by/4.0/), which permits unrestricted use, distribution, and reproduction in any medium, provided the original work, first published in JMIR Formative Research, is properly cited. The complete bibliographic information, a link to the original publication on http://formative.jmir.org, as well as this copyright and license information must be included. 